\title{
AFAMÍLIA RURAL EM FASES DE TRANSIÇÃO: MUDANÇAS NOS PAPÉIS E TAREFAS DO CUIDADO FAMILIAL
}

Gisele Cristina Manfrini Fernandes ${ }^{1}$, Astrid Eggert Boehs ${ }^{2}$

\begin{abstract}
RESUMO: O desenvolvimento da família ocorre através de etapas e de transições ao longo do tempo, gerando mudanças esperadas e/ou inesperadas. Este artigo objetiva apresentar aspectos das mudanças nos papéis, nas tarefas e no cuidado familial de duas famílias rurais, de três e quatro gerações, residentes em um município do Médio Vale do Itajaí, Santa Catarina. É uma pesquisa convergente assistencial, cuja coleta de dados se deu durante a assistência, complementada com entrevista, genograma, ecomapa e observação. A análise dos dados foi de conteúdo e os resultados foram discutidos na perspectiva do ciclo vital familiar. As transições maturacionais revelam o processo de transmissão da herança, o desafio dos casais jovens diante dos papéis parentais e em construir um modelo familiar próprio, com participação de outros membros. As transições situacionais envolvem mudanças nas tarefas agrícolas e domésticas, na situação de doença na família e a negociação de papéis, como o de cuidador. Com este estudo, pudemos conhecer aspectos do desenvolvimento de famílias rurais e o seu cuidado, o que contribui para a assistência de enfermagem familiar neste contexto.
\end{abstract}

PALAVRAS-CHAVE: Enfermagem; Saúde da família; Saúde da população rural.

\section{RURALFAMILY IN TRANSITION: CHANGES INTHE ROLES, TASKS AND FAMILY CARE}

ABSTRACT: Family development occurs through stages and transitions over time, which leads to expected or unexpected changes. This article presents aspects of the changing roles, tasks and family care of two rural families, of three and four generations, living in a municipality from the Médio Vale do Itajaí, Santa Catarina state. It is a convergent-assistential research, which data collection took place during the assistance, supplemented by interviews, genogram, ecomap and observation. Data and content analysis was performed and the results were discussed by the family's vital cycle perspective. The expected maturational transitions show the process of family inheritance, the challenge of young couples facing parental roles and on building their own family model with other members' participation. The unexpected situational transitions involve changes in agricultural and domestic tasks, in the situation of family illness and negotiation of roles, such as the caregiver one. Through the development of this study we could find out the aspects of the rural families' development and their care, which could contribute to family nursing care within this context.

KEYWORDS: Nursing; Family health; Rural health.

\section{LAFAMILIA RURAL EN FASES DE TRANSICIÓN: MUDANZAS EN LOS PAPELES Y TAREAS DEL CUIDADO FAMILIAR}

RESUMEN: El desarrollo de la familia ocurre a través de etapas y de transiciones a lo largo del tiempo, generando mudanzas esperadas y/o inesperadas. Este artículo objetiva presentar aspectos de las mudanzas en los papeles, en las tareas y el cuidado familiar de dos familias rurales, de tres y cuatro generaciones, residentes en un municipio del Medio Valle de Itajaí/Santa Catarina. Es una investigación convergente asistencial, cuya recolección de datos se dio durante la asistencia, complementada con entrevista, genograma, ecomapa y observación. El análisis de los datos fue de contenido y los resultados fueron discutidos con la perspectiva del ciclo vital familiar. Las transiciones de madurez revelan el proceso de transmisión de la herencia, el desafío de las parejas jóvenes delante de los papeles parentales y en construir un modelo familiar propio, con participación de otros miembros. Las transiciones situacionales envuelven mudanzas en las tareas agrícolas y domésticas, en la situación de enfermedad en la familia y la negociación de papeles, como el de cuidador. Con este estudio podemos conocer aspectos del desarrollo de familias rurales y su cuidado, lo que contribuye para la asistencia de enfermería familiar en este contexto.

PALABRAS CLAVE: Enfermería; Salud de la familia; Salud rural.

${ }^{1}$ Enfermeira. Mestre. Doutoranda pelo Programa de Pós-Graduação em Enfermagem da Universidade Federal de Santa Catarina-PEN/ UFSC. Bolsista CNPq. Membro do Núcleo de Extensão e Pesquisa em Enfermagem e Promoção da Saúde-NEPEPS.

${ }^{2}$ Enfermeira. Doutora. Professora do Departamento de Enfermagem e do PEN/UFSC. Coordenadora do NEPEPS.

Autor correspondente:

Astrid Eggert Boehs

Universidade Federal de Santa Catarina

Rua Valter Castelan, 429 - 88037-300 - Florianópolis-SC, Brasil

Recebido: 17/09/09

E-mail: astridboehs@hotmail.com

Aprovado: 23/12/09 


\section{INTRODUÇÃO}

Estudos brasileiros na temática da atuação da enfermagem junto à família no contexto rural podem ser considerados escassos entre o período de 2000 a 2005. Entre os estudos encontrados destacam-se os que retratam a realidade rural de comunidades do Estado do Rio Grande do Sul ${ }^{(1-3)}$, os quais consideram alguns aspectos do desenvolvimento da família ${ }^{(1,4)}$ como as questões geracionais e a estrutura familiar. A perspectiva do desenvolvimento também foi utilizada como referencial teórico em uma pesquisa ${ }^{(5)} \mathrm{com}$ famílias idosas de uma área rural de Santa Catarina.

O cuidado à família rural é tratado nos estudos da enfermagem, através da abordagem ecológica ${ }^{(1)} \mathrm{e}$ etnográfica ${ }^{(2,6)}$, que proporcionam uma compreensão acerca da construção cultural de uma realidade de saúde e de doença de famílias de agricultores. Houve um estudo ${ }^{(7)}$ que procurou compreender o significado cultural da sexualidade de mulheres de uma comunidade rural; outros, que seguiram a linha teórica da compreensão cultural do cuidado na enfermagem, utilizaram a Teoria da Universalidade e Diversidade do Cuidado Cultural, de Madeleine Leininger ${ }^{(4,8-9)}$.

Nas famílias de colonos alemães do Rio Grande do Sul, as mulheres aparecem como responsáveis pelo cuidado dentro da família, aprendido desde a vida na infância, contemplando desde noções de preparo dos alimentos até a plantação na horta e no jardim. Assim como nas situações de doença, são elas que decidem quais as ações de cuidado devem ser efetuadas; lideram as decisões sobre o itinerário terapêutico ${ }^{(2,10)}$.

Neste sentido, percebe-se a necessidade de conhecer melhor o modo de viver das famílias em comunidades rurais e o cuidado familial, tendo em vista os diversos contextos rurais em que a Enfermagem se faz presente, especialmente através da Estratégia de Saúde da Família (ESF). O cuidado familial é um fenômeno investigado na enfermagem e se constitui nas

ações e interações presentes na vida de cada grupo familiar e se direciona a cada um de seus membros, individualmente ou ao grupo como um todo ou em parte, objetivando seu crescimento, desenvolvimento, saúde e bem-estar, realização pessoal, inserção e contribuição social ${ }^{(11: 17)}$.

É importante conhecer o cuidado nas famílias rurais em situações de transição desenvolvimental, assim como as mudanças decorrentes nos papéis e nas tarefas familiares. Acredita-se, neste sentido, que no desenvolvimento da família rural há mudanças nos papéis e nas tarefas que incluem os cuidados peculiares no contexto de vida. Assim, questiona-se: como tem ocorrido a mudança nos papéis e tarefas referente ao cuidado familial das famílias rurais diante de uma situação de transição?

O objetivo deste estudo é apresentar aspectos das mudanças nos papéis e tarefas da família rural do cuidado familial em situações de transição situacionais e maturacionais.

Como referencial teórico se utilizou a perspectiva do ciclo vital familiar ${ }^{(12)}$, a qual focaliza as mudanças através de diferentes estágios. No Brasil, destaca-se uma classificação ${ }^{(13)}$ do ciclo vital, a partir de estudos com famílias paulistas do estrato médio: 1) fase de aquisição; 2) fase adolescente; 3) fase madura e 4) fase tardia, as quais são adotadas no presente estudo.

As etapas da vida familiar são marcadas por transições. Estas estão relacionadas com as mudanças das fases de desenvolvimento: os maturacionais, associados com eventos na vida individual de algum dos membros e que envolve o grupo familiar, como o nascimento dos filhos, o casamento; e os situacionais ou nodais, associados com eventos inesperados, como doença ou morte por acidente, entre outros ${ }^{(14)}$.

Nesta perspectiva teórica, a família se constitui em um sistema interrelacionado, de tal forma que não ocorre mudança em uma parte sem uma série de mudanças resultantes em outras partes ${ }^{(15)}$ e, semipermeável, que significa não ser inteiramente independente de outros sistemas sociais, mas também não completamente dependente ${ }^{(16)}$. Envolve a história das gerações e considera também o desenvolvimento dos indivíduos, supondo-se uma simultaneidade entre a fase de vida da família e a fase de vida de cada membro $^{(17)}$.

As tarefas de desenvolvimento constituem conjuntos de normas crescentes a partir de determinada fase de uma posição familiar. Quando incorporado pelo ocupante da posição, como um papel ou parte de um grupo de papéis, traz sobre a integração um equilíbrio temporário no sistema, em relação a um complexo de papéis ou um jogo de complexo do papel. O fracasso para incorporar as normas leva à falta de integração, a aplicação de pressões normativas adicionais na forma de sanções e dificuldades em incorporar normas posteriores no conjunto de papéis da posição familiar(15)

\section{METODOLOGIA}

Trata-se de uma pesquisa qualitativa do tipo 
convergente-assistencial que "se revela pelos movimentos de aproximação, de distanciamento e de convergência com a prática, de maneira a criar espaços de superposição com a assistência”(18:72).

O estudo se deu em Município do Médio Vale do Itajaí, Santa Catarina ${ }^{(19)}$, colonizado principalmente por imigrantes europeus. A base da economia é a agricultura e madeireiras, indústrias têxteis e de fiação. A população do Município é de aproximadamente 9.000 habitantes, com uma população urbana de cinco mil habitantes e uma população rural de quatro mil habitantes, e predomínio masculino, conforme Censo de 2000 do IBGE ${ }^{(20)}$. O Município conta com quatro unidades de saúde com ESF e um hospital particular, ao qual a população tem acesso, além dos atendimentos especializados e aos hospitais públicos nos municípios vizinhos.

Para a seleção dos participantes considerou-se como critérios de inclusão: famílias com um ou mais membros nascidos no Município do estudo; moradia na área rural de abrangência da ESF; que estivesse na etapa de aquisição da vida familiar (casal com filho pequeno); e a aceitação da família para participação no estudo. O critério de exclusão consistiu em ser famílias migrantes de outros Municípios ou Estados.

Participaram duas famílias - Girassol e Rosa (nomes fictícios), ambas apresentavam núcleos em diferentes fases de desenvolvimento, caracterizando a presença de três e quatro gerações respectivamente, residentes na área rural assistida pela ESF.

Nos encontros com as famílias, foram realizadas entrevistas semiestruturadas, com roteiro de perguntas para obtenção de informações de identificação, informações sobre o cuidado familial, sobre o cotidiano de vida e para elaboração do genograma e ecomapa ${ }^{(21)}$. As entrevistas foram gravadas, e os demais dados de observação e diálogos que ocorreram durante o cuidado foram registrados imediatamente após cada encontro. Os genogramas e ecomapas foram elaborados no primeiro encontro, com complementação de dados nos encontros subsequentes. A análise e a interpretação dos dados da pesquisa foram efetuadas pelo método da análise de conteúdo de Bardin ${ }^{(22)}$, com etapas de: pré-análise e organização do material coletado; seleção de unidades de registro (trechos das entrevistas) e de unidades de significado ou códigos; síntese das unidades de significação e construção de categorias; interpretação e discussão dos resultados (categorias) com base no referencial teórico.
A entrada nas famílias foi iniciada pelo cuidado aos núcleos em aquisição, através do acompanhamento do crescimento e desenvolvimento das crianças, primeiramente na Unidade de Saúde e, posteriormente, com encontros nos domicílios, que foram abrangendo o cuidado a outros núcleos familiares (fase madura e tardia). Na família Rosa os cuidados no domicílio foram direcionados à situação decorrente de acidente ofídico com a bisavó e necessidade de suporte aos cuidados com a ferida. No caso da família Girassol, as visitas estavam voltadas para acompanhamento e orientação acerca do controle da hipertensão arterial do casal maduro. Nestes encontros participaram 14 pessoas, durante 9 meses (outubro de 2004 a julho de 2005), totalizando três visitas à família Girassol e seis visitas à família Rosa. Foram entrevistadas quatro pessoas na família Girassol e cinco pessoas na família Rosa, pois alguns dos membros não estiveram presentes nos encontros agendados para entrevista.

Os aspectos éticos da pesquisa contemplam a Resolução 196/96, além da aprovação pelo Comitê de Ética da Universidade Federal de Santa Catarina, sob protocolo no 252/2004.

\section{RESULTADOS E DISCUSSÃO}

\section{Genograma e Ecomapa}

Conforme o genograma, a família Girassol é composta de um núcleo em aquisição (casal jovem, 26 e 22 anos, com um filho de um ano e três meses) e um núcleo maduro (pais do jovem, 64 e 62 anos), que residem em mesma moradia. Todos os membros são de origem germânica, falam a língua alemã e pertencem à Igreja Evangélica Luterana. O avô da criança está aposentado e trabalha na propriedade junto à esposa, ao filho e à nora. $\mathrm{O}$ jovem auxilia nas atividades agrícolas e também trabalha como eletricista; já a esposa é costureira, mas deixou o emprego com o nascimento do bebê.

A família Rosa, por sua vez, reside em uma localidade distante 22 quilômetros da Unidade de Saúde, sendo constituída de quatro núcleos que se distribuem em três moradias bastante próximas. Há dois núcleos familiares na fase de aquisição: um deles (21 e 20 anos) com um filho de seis meses e, o outro casal (24 e 21 anos), com um filho de três anos, cada qual em sua casa. Na outra moradia, há um casal na fase madura, responsável pelo cuidado da bisavó viúva e que se constitui no núcleo tardio da família. Todos 
ajudam nos trabalhos da propriedade agrícola e um dos cônjuges de um dos casais jovens também trabalha em uma serraria local. Os membros dela também possuem origem germânica, falam a língua alemã e pertencem à Igreja Evangélica Luterana. Apenas um membro agregado, o pai da criança atendida, possui origem italiana e o casal em aquisição pertence à religião católica. A agricultura de subsistência e a venda de produtos agrícolas é parte da renda da maioria das famílias na comunidade estudada.

\section{Mudanças nos papéis e tarefas da família em transição maturacional}

Em ambas as famílias foi possível identificar as transições maturacionais, relacionadas a eventos de vida esperados, com relação aos indivíduos e que envolvem a família num todo.

A ocasião do adoecimento, tanto no núcleo maduro da família Girassol, quanto no núcleo tardio da família Rosa, levou-as a discutirem sobre a herança e a tomarem algumas decisões. A tomada de decisão se deu na presença de todos os filhos e, dentre os critérios de escolha, consideraram a disponibilidade de manter a propriedade e a responsabilidade em cuidar dos pais idosos ou viúvos. A autoridade do chefe da família é lembrada em uma das famílias entrevistadas como o responsável pelas decisões acerca da propriedade rural e sobre a transmissão da herança, revelando que:

Por enquanto é o velho que decide. (avó Girassol)

Isto está em consonância com a afirmação de outros autores de que a família na fase tardia disponibiliza aos filhos o seu esforço de anos de trabalho, desfazendo-se dos bens e os dividindo, como forma metafórica de despedida do papel funcional de provedor $^{(17)}$.

Os membros da família Girassol e da família Rosa estavam voltados para as tarefas do núcleo em aquisição, tendo em vista a presença de crianças menores de idade em casa e a adaptação às mudanças nos papéis familiares. A presença do filho demanda muitas atividades, além daquelas que já eram realizadas anteriormente.

Só aumentou o serviço! (mãe Rosa)

Os papéis parentais são respeitados em cada núcleo familiar. Os casais jovens tomam suas próprias decisões, principalmente quando se trata das necessidades dos filhos e, quando há dúvidas para a decisão, recorrem à opinião dos mais velhos.

Mesmo próximos das famílias de origem, os núcleos de aquisição restringem alguns aspectos desta relação familiar, buscando a privacidade e a autonomia diante dos planos de vida, inclusive sobre a construção de um modelo familiar próprio. Estudos anteriores indicam que as relações com as famílias de origem passam por negociações hierárquicas de poder e competência, para manutenção ou substituição de tradições nos hábitos e costumes educacionais presentes nas gerações anteriores ${ }^{(14)}$.

A educação das crianças se apresenta como uma das principais tarefas da fase de aquisição e a responsabilidade desta é compartilhada com os avós, que estão atentos ao crescimento e desenvolvimento dos netos. Também procuram contribuir com a sua experiência de vida familiar, orientando os filhos a levarem em consideração o modelo de educação da família, e também auxiliam no cuidado diário da criança. O cuidado diário em família possibilita educar a criança, levando em consideração modelos de vida comuns entre as gerações. Conforme a literatura de enfermagem, o cuidado familial se traduz em atitudes e valores que orientam para a vida ${ }^{(11)}$, como mencionado pelas famílias do estudo, ao dialogar, fazer as refeições juntos à mesa, rezar e agradecer pelos alimentos e ensinando às crianças o valor da fé.

Com o crescimento e o desenvolvimento dos filhos surgem outras tarefas e o cuidado incorpora mudanças no ambiente doméstico para proteção e segurança das crianças. Uma das mães se refere à introdução de outros alimentos à criança como uma tarefa difícil e revela algumas crenças a respeito do leite materno:

Parei de dar maçã porque achei que fosse fazer mal junto com o leite [...]. (mãe Rosa)

Esta situação exemplifica as simultaneidades entre as mudanças relacionadas ao desenvolvimento individual, no caso, a transição alimentar do lactente, e as tarefas desenvolvimentais da própria fase familiar, ou seja, a adaptação da jovem mãe aos cuidados com a criança pequena. Esta observação vai ao encontro da idéia de que as famílias com filhos pequenos se reorganizam a cada nova fase de desenvolvimento dos filhos, de modo a atender as novas demandas que

Cogitare Enferm 2010 Jan/Mar; 15(1):33-9 
surgem $^{(17)}$. E na família rural, a proximidade dos núcleos permite maior interação entre as gerações, servindo tanto como suporte às jovens mães, como oportunidade de partilhar experiências de cuidado materno que são negociados e avaliados pelos núcleos em aquisição para constituir seu modelo de vida.

Nos eventos de transição maturacional, descritos acima, o papel da enfermeira no cuidado esteve presente no diálogo e na escuta sobre aspectos relacionados às experiências maternas, às dúvidas e inseguranças quanto a alguns cuidados com a alimentação, higiene e proteção da criança; assim como nas trocas de experiência e de saberes com outros membros envolvidos com as tarefas centradas no núcleo de aquisição. À medida que a enfermeira conhece a família em seu ciclo vital, percebe o cuidado familial, atenta-se para a identificação de áreas de preocupação ou fragilidades da família e direciona seu cuidado para fortalecê-la.

Este movimento crítico e interacional de aproximações e distanciamentos entre o método de pesquisa convergente assistencial e a assistência/ cuidado permite trocas recíprocas de informações entre ambos os processos, ao mesmo tempo em que preserva a autonomia de cada um deles, constituindose como ponte e base comum à construção do conhecimento novo dessa prática assistencial ${ }^{(23)}$.

\section{Mudanças nos papéis e tarefas da família em transição situacional}

O adoecimento decorrente de acidente ofídico sofrido pela bisavó mobilizou os demais membros da família Rosa para a busca de atendimento e hospitalização, repercutindo em mudanças inesperadas em tarefas e papéis familiares, caracterizando uma transição situacional. Especialmente nestas transições, as famílias revelaram com quem podem contar para ajuda, cujos dados se expressaram no ecomapa.

As tarefas anteriormente desempenhadas pela bisavó foram distribuídas entre os membros dos demais núcleos para o funcionamento desta família rural. Eles referem que cada um faz a sua parte e cada um ajuda um pouco, mostrando uma dinâmica recíproca para manutenção e reorganização da vida diária. Estar doente e não contribuir no trabalho requer ajuda dos próprios membros da família ou de outros, como os vizinhos que, ao se envolverem, também experimentam mudanças temporárias ou não, em algumas de suas tarefas.
Neste sentido, a doença repercute na vida do indivíduo e também da família, especificamente na sua organização diária, visto que "modificações na rotina e o convívio com limites necessários à provisão dos cuidados para com o doente são aspectos importantes para a nova situação”(14:48). Na presença da doença, o cuidado familial se mostra como elemento articulador do sistema familiar de saúde.

Alguns papéis são (re)negociados entre os núcleos das gerações mais jovens e mais velhas na família rural, entre eles o papel de cuidador. Os núcleos de aquisição se envolvem com as tarefas e funções designadas: na família Rosa, a neta que mora perto passou a cuidar da bisavó. A proximidade entre as moradias é uma característica do contexto rural estudado e parece ser um fator facilitador para suporte entre os membros no cuidado e à ajuda nas tarefas e papéis. Os membros que residem longe participam com o compromisso/tarefa de visitar os pais adoecidos.

Realizar alguns cuidados aprendidos com profissionais da saúde no domicílio e acompanhar as hospitalizações são tarefas, na maioria das vezes, compartilhadas entre as mulheres da família ou, às vezes, revezados entre os demais membros, especialmente quando há algum impedimento àquele escolhido como o cuidador.

Agora que eu tenho a pequena não posso cuidar dela no hospital [...] a minha cunhada também estava com o filho dela com amidalite, então ela também não pode ir [...]. (mãe Rosa)

Nesta situação, as visitas da enfermeira também incluíram alguns cuidados direcionados à bisavó adoecida e à família que se dispunha a trocar curativos no domicílio. Vale destacar que o apoio da equipe de saúde e da enfermagem é importante nestas transições, especialmente quando se trata do cuidado na área rural, porque comumente não acontece esta aproximação e estas ocasiões merecem ser observadas.

Na família Girassol, a transição situacional se refere a dois eventos relacionados ao núcleo na fase de aquisição: a gravidez não planejada que levou o jovem casal a morar na casa dos pais do cônjuge e, a perda financeira decorrente de danos com o automóvel que repercutiu nos planos e despesas da família num todo. Neste caso, o conflito de valores entre o núcleo de aquisição e o núcleo maduro a respeito da gravidez antes do casamento implicou em conflitos e dificuldade nesta etapa de vida familiar. 
No início a gente não queria aceitar porque achava que eles deveriam se casar [...]. (avô Girassol)

Para o núcleo maduro, a adaptação às mudanças requer uma acomodação da estrutura e do funcionamento familiar, como um fenômeno gradativo que inclui alguns processos como incorporar novos papéis, rever relações hierárquicas, consolidar valores significativos à identidade familiar, preservar alguns costumes e mudar outros para atender às novas necessidades e ampliar a rede social, consolidando também as antigas relações ${ }^{(17)}$.

A chegada do membro agregado (nora) no mesmo espaço da moradia trouxe mudanças nas relações e fronteiras para o desempenho do papel de chefe de família, que passou a ser dividido entre pai e filho e, dentre as tarefas, a responsabilidade dividida entre a sogra e a nora na organização do lar e das refeições. Conforme a literatura, este processo de mudança requer flexibilidade da família quanto a alguns aspectos importantes como a comunicação, a combinação de regras de convivência, a acomodação às novas situações de espaço, a busca de soluções conjuntas e mudanças de hábitos ${ }^{(14)}$.

Além disso, os núcleos se voltam para as tarefas de dedicação ao cuidado à criança e à adaptação aos novos papéis. No caso da mãe Girassol, o abandono do emprego na fábrica têxtil, após o nascimento do filho, permitiu assumir novas tarefas no espaço doméstico e uma inserção gradativa em tarefas agrícolas compartilhadas com a sogra, paralelamente às mudanças no crescimento e desenvolvimento da criança. A inserção da jovem mãe no trabalho agrícola e a inserção do jovem pai no trabalho autônomo são também, para este núcleo de aquisição, uma transição situacional, onde adquirir recursos parece ser tarefa essencial com o nascimento do primeiro filho.

A iminência de complicações na condição de saúde do casal maduro interferiu também no desempenho de algumas de suas tarefas agrícolas, em função das necessidades de repouso e cuidados direcionados ao controle da hipertensão arterial. A jovem assume um novo papel de cuidadora diante da incorporação de cuidados diários para tratamento da doença crônica, orientados pelos profissionais da saúde, como exemplo, lembrar os horários das medicações, preparar a comida com menor teor de sal, acompanhar nas consultas médicas.

\section{CONCLUSÃO}

Retomando o objetivo do estudo, que foi de apresentar aspectos das mudanças nos papéis e tarefas da família rural referente ao cuidado familial em situações de transição, percebe-se que as famílias revelaram a participação dos diversos membros para o convívio diário em casa e no trabalho agrícola. O cuidado, por sua vez, aparece como uma importante tarefa nestas famílias e está presente em todos os núcleos, especialmente direcionado a alguns membros, quando na transição situacional. O cuidado das famílias está voltado para a saúde dos indivíduos, especialmente das crianças, para a recuperação na situação de doença, e também à saúde da família, quando considera valores para a vida e organiza tarefas e papéis para 0 melhor funcionamento familiar.

Com o desenvolvimento da pesquisa convergente-assistencial, a qual almeja também contribuir para as questões da prática do cuidado de enfermagem e assistência em saúde, pode-se destacar que o estudo oportunizou conhecer o viver e o cuidar de famílias rurais sob a perspectiva teórica do desenvolvimento familiar. As mudanças do ciclo vital puderam ser conhecidas, mostrando-se um processo dinâmico em que a enfermeira tem inúmeras possibilidades para cuidar e papel fundamental no fortalecimento do cuidado familial. Os eventos de transição são marcos na vida familiar e repercutem na interação entre os membros para a organização, o funcionamento e o cuidado, conforme revelado pelos diferentes núcleos estudados.

A reciprocidade nas relações de ajuda entre os membros da família rural e, em alguns casos também de outros, permite a adaptação às mudanças nas tarefas de desenvolvimento e o enfrentamento das dificuldades e das necessidades de cuidado que surgem com os eventos de transição.

As limitações deste estudo se referem ao número de famílias estudadas, no entanto, os resultados possibilitaram conhecer os papéis e as tarefas das famílias em eventos de transição e contribuem para repensar caminhos e possibilidades para o cuidado de enfermagem no contexto rural, onde o acesso a recursos e a serviços de saúde é mais restrito. Sugerese que a enfermagem e outros profissionais das ESF abordem a família com olhar sobre as mudanças do ciclo vital, investindo na educação em saúde nos espaços da própria comunidade e, nas visitas domiciliares, aproximando-se das famílias e oportunizando o cuidado compartilhado, considerando as forças e as fragilidades do cuidado familial. O papel 
da enfermeira é cuidar com conhecimento e conhecer para melhor cuidar.

\section{REFERÊNCIAS}

1. Schwartz E. Família, ruralidade e saúde. Ciênc Cuid Saúde. 2003; 2 (supl):38-41.

2. Heck RM. Contexto sociocultural dos suicídios de colonos alemães: um estudo interdisciplinar para a Enfermagem [tese]. Florianópolis: Universidade Federal de Santa Catarina; 2000.

3. Budó MLD. A prática de cuidados em comunidades rurais e o preparo da enfermeira [tese]. Florianópolis: Universidade Federal de Santa Catarina; 2000.

4. Schwartz E. Família teuto-gaúcha: o cuidado entre possibilidades e limites [dissertação]. Florianópolis: Universidade Federal de Santa Catarina; 1998.

5. Elsen I, Rosa MC, Araújo MA, Cardoso DE. A família idosa numa área rural de Santa Catarina: seu significado e suas relações sociais. Texto Contexto Enferm. 1997 Mai/Ago; 6(2):359-68.

6. Denardin ML. A família rural e os cuidados em saúde. In: Elsen I, Marcon SS, Santos MR, organizadoras. O viver em família e sua interface com a saúde e a doença. Maringá: Eduem; 2002.

7. Cavalcanti MSL. Gosto de ser mulher: representação da sexualidade feminina em uma comunidade rural [tese]. Ribeirão Preto: Universidade de São Paulo; 1998.

8. Budó MLD. A mulher como cuidadora no contexto de uma comunidade rural de imigração italiana. Texto Contexto Enferm. 1997 Jan/Abr;6(1):181-97.

9. Portella MR. Cuidar para um envelhecer saudável: a construção de um processo educativo com mulheres de uma comunidade rural de Passo Fundo/RS [dissertação]. Florianópolis: Universidade Federal de Santa Catarina; 1998.

10. Heck RM. Percepção social sobre categorias de risco do suicídio entre colonos alemães do Nordeste do Rio Grande do Sul. Texto Contexto Enferm. 2004 Out/ Dez;13(4):559-67.

11. Elsen I. Cuidado familial: uma proposta inicial de sistematização conceitual. In: Elsen I, Marcon SS, Santos MR, organizadoras. O viver em família e sua interface com a saúde e a doença. Maringá: Eduem; 2002.
12. Carter B, McGoldrick M, colaboradores. As mudanças no ciclo de vida familiar: uma estrutura para a terapia familiar. Porto Alegre: Artes Médicas; 1995.

13. Cerveny CMO, Berthoud CM, colaboradores. Família e ciclo vital: nossa realidade em pesquisa. São Paulo(SP): Casa do Psicólogo; 1997.

14. Vicente RMPS. Família e mudança. In: Cerveny CMO, organizadora. Família e comunicação, divórcio, mudança, resiliência, deficiência, lei, bioética, doença, religião e drogadição. São Paulo: Casa do Psicólogo; 2004.

15. Rowe GP. The developmental conceptual framework to de study of the family. In: Nye S, Berardo F. Emerging conceptual frameworks in familys analysis. New York: Praeger; 1981.

16. Klein DD, White JM. Family theories: an introduction. Thousands Oaks: Sage; 1996.

17. Cerveny CMO, Berthoud CM. Visitando a família ao longo do ciclo vital. São Paulo(SP): Casa do Psicólogo; 2002.

18. Trentini M, Paim L. Pesquisa convergente-assistencial: um desenho que une o fazer e o pensar na prática assistencial em saúde-enfermagem. $2^{\mathrm{a}}$ ed. Florianópolis: Insular; 2004.

19. Manfrini GC. O cuidado às famílias rurais, com base na teoria do desenvolvimento da família [dissertação]. Florianópolis: Universidade Federal de Santa Catarina; 2005.

20. IBGE. Censo Demográfico 2000. [acesso em 2005 Fev 18]. Disponível: http://www.ibge.gov.br.

21. Wright LM, Leahey M. Enfermeiras e famílias: um guia para avaliação e intervenção na família. $3^{a}$ ed. São Paulo(SP): Roca; 2002.

22. Bardin L. Análise de conteúdo. $3^{\mathrm{a}}$ ed. Lisboa: Edições 70; 2004.

23. Paim L, Mercedes T, Madureira VSF, Stamm M. Pesquisa convergente-assistencial e sua aplicação em cenários da enfermagem. Cogitare Enferm. 2008 Jul/Set;13(3):380-6. 